\title{
Elektrik Enerjisi Üreten Şirketlerin Covid-19 Salgın Ortamındaki Finansal Performanslarının ROC ve SMART Bütünleşik Yaklaşımı ile Analizi'
}

\section{Analysis of the Financial Performances of Electric Energy Producing Companies in The Covid-19 Epidemic with ROC and SMART Integrated Approach}

\author{
Murat Kemal KELEŞ²* \& İlknur Ülkü ARMAĞAN ${ }^{3}$ \& Aşkın ÖZDAĞOĞLU ${ }^{4}$ \\ Geliş / Received: 07/10/2021 \\ Revize / Revised:18/10/2021 \\ Kabul / Accepted: 18/10/2021
}

\begin{abstract}
ÖZ
Gelişen teknoloji, küreselleşen piyasalar, yapısal regülasyonlar ve artan nüfus doğrultusunda artan enerji talebinin etkisi ile tüm dünyada enerji sektörü yıldan yıla büyümektedir. Enerji sektörü içinde en büyük paya da elektrik enerjisi sahiptir. Elektrik üretimi, sanayi sektörü için dolayısı ile de ülke ekonomileri için en önemli girdi niteliğindedir. Tüm dünyada olduğu gibi Türkiye'de de Covid-19 pandemisi nedeniyle elektrik üretimi ve elektrik tüketimi bu süreçten etkilenmiştir. Bu çalışmanın amacı, Borsa İstanbul Elektrik Endeksinde (XELKT) işlem gören elektrik üretimi yapan halka açık şirketlerin Covid-19 pandemi ortamındaki finansal performansını değerlendirmektir. Değerlendirmede, Borsa İstanbul bünyesindeki XELKT endeksinde işlem gören yedi adet elektrik üreten enerji şirketine ait Kamuyu Aydınlatma Platformu (KAP) 'tan alınan 2020 y1lı konsolide mali tablo verileri kullanılmıştır. Çalışmanın analizlerinde çok kriterli karar verme yöntemlerinden ROC ve SMART yöntemleri bütünleşik olarak kullanılmıştır. ROC (Rank Order Centroid) yöntemi ile değerlendirme kriterlerinin ağırlıkları bulunmuş, SMART (Simple Multi-Attribute Rating Technique) yöntemi ile de elektrik enerjisi üreten yedi şirketin finansal performansı değerlendirilerek performans sıralaması yapılmıştır. 2020 yılı finansal performans sıralamasında ilk sırada AKSA Enerji Üretim A.Ş., son sırada da ZORLU Enerji Elektrik Üretim A.Ş. yer almıştır. Finansal performans değerlendirilmesi yapılan çalışmalarda çok kriterli karar verme yöntemlerinin kullanıldığı çalışmalara sıklıkla rastlanmaktadır. Ancak elektrik enerjisi üreten şirketlerin finansal performans değerlendirmesinde ROC ve SMART yöntemlerinin bütünleşik olarak kullanıldığı bir çalışmaya rastlanmamıştır. Çalışmanın bu yönüyle literatüre katkı yapacağı ve sektöre fayda sağlayacağı düşünülmektedir.
\end{abstract}

Anahtar Kelimeler- Covid-19, Finansal Performans, Çok Kriterli Karar Verme, ROC yöntemi, SMART Yöntemi

\footnotetext{
${ }^{1} \mathrm{Bu}$ çalışma, Isparta Uygulamalı Bilimler Üniversitesi Bilimsel Araştırma ve Yayın Etiği Kurulu'ndan 24.09.2021 tarihli (Toplantı Sayısı: 65, Karar No:07) "Etik Kurul Onayı" alınarak üretilmiştir.

2 *Sorumlu Yazar, Dr. Öğr. Üyesi, Isparta Uygulamalı Bilimler Üniversitesi, Keçiborlu Meslek Yüksekokulu, Ulaştırma Hizmetleri Bölümü, muratkeles@isparta.edu.tr, (https://orcid.org/0000-0003-0374-6839)

${ }^{3}$ Öğr. Gör., Isparta Uygulamalı Bilimler Üniversitesi, Keçiborlu Meslek Yüksekokulu, ulkuarmagan@isparta.edu.tr, (https://orcid.org/0000-0003-0542-0007)

${ }^{4}$ Doç. Dr., Dokuz Eylül Üniversitesi, İşletme Fakültesi, İşletme Bölümü, askin.ozdagoglu@deu.edu.tr, (https://orcid.org/00000001-5299-0622)
} 


\begin{abstract}
The energy sector is growing all over the world with the effect of increasing energy demand due to developing technology, globalizing markets, structural regulations, and increasing population. Electrical energy has the largest share in the energy sector. Electricity production is the most important input for the industrial sector and therefore for the economies. As in the whole world, electricity production and electricity consumption in Turkey have been affected by this process due to the Covid-19 pandemic. The purpose of this study is to evaluate the financial performance of electricity generation companies traded in the Borsa Istanbul Electricity Index (XELKT) during the Covid-19 pandemic. In the evaluation, seven electricity generating energy companies traded in the XELKT index of Borsa Istanbul were selected. Consolidated financial statement data of companies for 2020 are taken from Public Disclosure Platform (PDP). ROC and SMART methods, which are multi-criteria decision-making methods, were used in the analysis of the study. The weights of the evaluation criteria were found with the ROC (Rank Order Centroid) method, and the performance ranking was made by evaluating the financial performance of seven electrical energy producing companies with the SMART (Simple Multi-Attribute Rating Technique) method. In the financial performance ranking of 2020, AKSA Energy Generation took the first place and ZORLU Energy Electricity Generation took the last place. Although multi-criteria decision-making methods are frequently used in financial performance evaluation, no study has been found in which ROC and SMART methods are used in the financial performance evaluation of electrical energy producing companies. It is thought that this study will contribute to the literature and will be beneficial to the sector.
\end{abstract}

Keywords- Covid-19, Financial Performance, Multi Criteria Decision Making, ROC method, SMART Method

\title{
I. GİRIŞ
}

Dünyada 2020 y1lı toplam elektrik üretimi 25 bin 850 teravatsaat (TWh) (EMBER, 2021), Türkiye'de ise elektrik üretimi 291 milyar 552 milyon kilovatsaat (KWh), elektrik tüketimi ise 290 milyar 856 milyon KWh 'tir. Türkiye'de hidrolik, rüzgâr, jeotermal, biyokütle, güneş, kömür gibi birçok kaynaktan elektrik üretimi yapılmaktadır. Enerji Piyasası Düzenleme Kurumu (EPDK)'nın 2020 yılı sonu verilerine göre ülkemizde toplam 2528 lisanslı elektrik üretim tesisi bulunmakta ve 294.084,7 GWh lisanslı elektrik üretimi yapılmaktadır (EPDK, 2020:4-7).

Özellikle sanayi sektörünün bir göstergesi olduğu için ülke ekonomilerinde ekonomik büyümenin en önemli parametrelerden biri elektrik talebidir. Tüm diğer sektörler gibi Covid-19 pandemisinden elektrik talebi de etkilenmiştir. Fakat Türkiye'de devam eden pandemi sürecine karşı alınan tedbirler ve destek paketleri ile 2020 Haziran ayında elektrik talebi tekrar yükselişe geçmiştir. Bu olumlu gelişmede sanayi sektöründe üretimin tekrar artması ve virüsün bulaşma riskine karşı sokağa çıkma kısıtlamaları ve çalışma şekli değişiklikleri ile hane halkının evde geçirdiği zamanın artması etkili olmuştur. Böylece Türkiye 2020 yılı sonunda elektrik talebinde bir önceki yıla göre \%0,8 artış sağlamış ve Covid-19 pandemisinden en az etkilenen ülkelerden biri olmuştur. (EPDK, 2020:9).

Elektrik enerjisinin çok önemli olduğu ülkemizde Borsa İstanbul'da (BIST) da Elektrik Endeksinde (XELKT) elektrik üreten halka açılmış şirketler işlem görmektedir. Bunlar Akenerji Elektrik Üretim A.Ş., AKSA Enerji Üretim A.Ş, Aksu Enerji ve Ticaret A.Ş., Ayen Enerji A.Ş., Enerjisa Enerji A.Ş., Odaş Elektrik Üretim Sanayi Ticaret A.Ş. ve Zorlu Enerji Elektrik Üretim A.Ş. ’dir. Bu çalışmanın amacı da BIST Elektrik Endeksinde (XELKT) işlem gören araştırma kapsamına dâhil edilen şirketlerin Covid-19 pandemi ortamındaki finansal performansını değerlendirmektir. Çalışmada, Kamuyu Aydınlatma Platformu (KAP)'tan alınan 2020 yılı yıllık konsolide mali tablo verileri kullanılmış ve finansal performans göstergesi rasyolarından "kaldıraç oranı", "cari oran”, "likidite oranı", “özsermaye kârlılığı” ve "özsermaye devir hızı” hesaplanmıştır.

Çalışmanın analizlerinde çok kriterli karar verme (ÇKKV) yöntemlerinden ROC (Rank Order Centroid) yöntemi ile değerlendirme kriterlerinin ağırlıkları bulunmuş, SMART (Simple Multi-Attribute Rating Technique) yöntemi ile de elektrik enerjisi üreten şirketlerin finansal performansı değerlendirilerek performans sıralaması yapılmıştır.

Çalışmada öncelikle literatür incelemesine yer verilmiş, daha sonra çalışmada kullanılan ROC ve SMART yöntemine ait adımlar anlatılmıştır. Devam eden aşamada BIST Elektrik Endeksinde işlem gören 


\begin{tabular}{|c|c|c|}
\hline & $\begin{array}{l}\text { BŞEÜ Sosyal Bilimler Dergisi } \\
6(2), 227-235,2021\end{array}$ & $\begin{array}{r}\text { BSEU Journal of Social Sciences } \\
\text { https://doi.org/10.33905/bseusbed.1005798 }\end{array}$ \\
\hline On & e-ISSS & V:2548-088X (https://dergipark.org.tr/tr/pub/bseusbed) \\
\hline
\end{tabular}

şirketlerin performanslarının değerlendirildiği uygulama bölümü bulunmaktadır. Çalışmaya ait sonuçlar ise son kısımda verilmiştir.

Bu çalışma için, Isparta Uygulamalı Bilimler Üniversitesi Bilimsel Araştırma ve Yayın Etiği Kurulu'ndan 24.09.2021 tarihli (Toplantı Sayısı: 65, Karar No:07) “Etik Kurul Onayı” alınmıştır.

\section{LITTERATÜR ARAŞTIRMASI}

Tablo 1.de, ÇKKV Yöntemlerinin kullanıldığı finansal performans üzerine yapılan çalışma örnekleri ve bu çalışmada kullanılan ROC ve SMART yöntemlerinin uygulandığı çalışmalardan çeşitli örnekler bulunmaktadır.

Tablo 1. Literatür Araştırması

\begin{tabular}{|c|c|c|}
\hline Çalışmanın yazarı/yazarları & Çalışmanın konusu & Kullanılan yöntem/ler \\
\hline \multicolumn{3}{|c|}{ ÇKKV Yöntemlerinin kullanıldığı FİNANSAL PERFORMANS üzerine yapılan çalıșma örnekleri } \\
\hline Topal (2021) & $\begin{array}{l}\text { Forbes } 500 \text { listesindeki } 10 \text { elektrik üretim } \\
\text { şirketinin } 2019 \quad \text { yll } \quad \text { finansal } \\
\text { performanslarının değerlendirilmesi }\end{array}$ & Entropi-CoCoSo \\
\hline Ansari vd.. (2021) & $\begin{array}{l}2008 \text { ila } 2018 \text { yılları arasında Tahran } \\
\text { Menkul Kıymetler Borsası'nda işlem } \\
\text { gören } 172 \text { şirketin finansal } \\
\text { performanslarının yatırımcının risk alma } \\
\text { davranışı açısından değerlendirilmesi }\end{array}$ & Karar Ağacı, TOPSIS, OWA \\
\hline Beller Dikmen (2021) & $\begin{array}{l}2015-2019 \text { tarihleri arasında Türkiye'de } \\
\text { elektrik enerjisi sektöründe faaliyet } \\
\text { gösteren şirketlerin finansal performans } \\
\text { analizi }\end{array}$ & Oran Analizi \\
\hline Bae vd.. (2021) & $\begin{array}{l}\text { Havayolu sektörü firmalarının finansal ve } \\
\text { operasyonel performanslarının analizi }\end{array}$ & Bulanık AHP ve TOPSIS \\
\hline Moon ve Min (2020) & $\begin{array}{l}\text { Kore'deki enerji sektöründe faaliyet } \\
\text { gösteren firmaların enerji verimliliği ve } \\
\text { finansal performans arasındaki ilişkinin } \\
\text { değerlendirilmesi }\end{array}$ & Veri Zarflama Analizi \\
\hline Mercan ve Çetin (2019) & $\begin{array}{l}\text { BIST elektrik endeksindeki yedi şirketin } \\
\text { finansal performanslarının analizi }\end{array}$ & COPRAS ve VIKOR \\
\hline Bağcı ve Yiğiter (2019) & $\begin{array}{l}\text { BIST'te faaliyet gösteren } 15 \text { enerji } \\
\text { şirketinin 2008-2017 tarihleri arasındaki } \\
\text { finansal performanslarının analizi }\end{array}$ & SD ve WASPAS \\
\hline \multicolumn{3}{|c|}{ ROC YÖNTEMI ILE YAPILAN ÇALIȘMALAR } \\
\hline Günen (2021) & $\begin{array}{l}\text { Kayseri'de güneş fotovoltaik (PV) } \\
\text { santralleri kurmak için alternatif yerlerin } \\
\text { siralanmasi }\end{array}$ & Coğrafi Bilgi Sistemleri, ROC ve AHP \\
\hline Ndruru (2020) & Medan bölge savcıllğ̆ için savcı seçimi & ROC ve ARAS \\
\hline Ribeiro vd. (2020) & $\begin{array}{l}\text { Elektronik sektöründe akıllı teknolojiler } \\
\text { için akım dönüştürücü teknolojilerinin } \\
\text { karşılaştırılmalı analizi }\end{array}$ & $\mathrm{ROC}$ \\
\hline Lubis vd. (2020) & $\begin{array}{lc}\text { Wisconsin-Madison } & \text { Üniversitesi } \\
\text { İstatistik Bölümü'ndeki } & \text { asistanların } \\
\text { performansının değerlendirilmesi }\end{array}$ & ROC, SAW ve MOORA \\
\hline Erkan ve Elsharida (2020) & Libya'da havalimanı yer seçimi & Coğrafi Bilgi Sistemleri, ROC ve AHP \\
\hline Mohammed vd. (2017) & $\begin{array}{l}\text { Malezya'daki bir devlet üniversitesinde } \\
\text { beş farklı e-öğrenme yönteminin } \\
\text { sılralanması }\end{array}$ & ROC ve TOPSIS \\
\hline Roszkowska (2013) & $\begin{array}{l}\text { Çok kriterli analizlerde bir dizi kriterin } \\
\text { sıralı sıralamasının sayısal ağırlıklara } \\
\text { dönüsttürmek için kullanılabilecek } \\
\text { yöntemlerin karşışaştırılması }\end{array}$ & ROC, AHP ve SAW \\
\hline \multicolumn{3}{|c|}{ SMART YÖNTEMI ILE YAPILAN ÇALIŞMALAR } \\
\hline Darmowiyono vd. (2021) & $\begin{array}{l}\text { Ağız yarası ürünlerinin seçiminde tüketici } \\
\text { bazında sıralanması }\end{array}$ & SMART \\
\hline
\end{tabular}




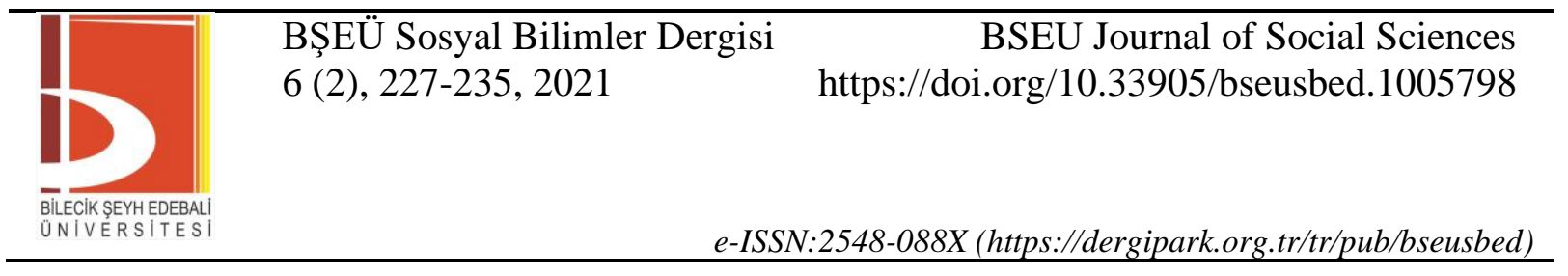

\begin{tabular}{|c|c|c|}
\hline Mahdiana ve Kusumawardhany (2020) & $\begin{array}{llr}\text { Budi Luhur Üniversitesi } & \text { Bilgi } \\
\text { Teknolojileri Fakültesi'ndeki } & \text { en } & \text { iyi } \\
& \text { öğretim üyesinin seçimi } & \\
\end{array}$ & AHP ve SMART \\
\hline Aksaraylı ve Pala (2019) & $\begin{array}{l}\text { Dokuz Eylül Üniversitesi Uzaktan Eğitim } \\
\text { hizmet kalitesinin değerlendirilmesi }\end{array}$ & $\begin{array}{c}\text { SMART, AHP ve SERVQUAL } \\
\text { Yaklaşımı }\end{array}$ \\
\hline Arslan (2019) & Demir-çelik işletmesi için personel seçimi & SMART ve TOPSIS \\
\hline Siregar vd. (2017) & $\begin{array}{l}\text { SMART yönteminin bir karar destek } \\
\text { sistemi olarak uygulanılabilirliğini test } \\
\text { etmek için yapılan bir örnek çalışma }\end{array}$ & SMART \\
\hline Konidari ve Mavrakis (2007) & $\begin{array}{l}\text { İklim değişikliğini azaltma politikası } \\
\text { araçlarının değerlendirilmesi }\end{array}$ & AHP, SMART ve MAUT \\
\hline Herişçakar (1999) & $\begin{array}{l}\text { Gemiler için gerekli olan ana makine } \\
\text { seçiminin yapılması }\end{array}$ & AHP ve SMART \\
\hline
\end{tabular}

\section{ROC (RANK ORDER CENTROID WEIGHT) YÖNTEMI}

ROC (Barron ve Barret, 1996) tarafından önerilen bir kriter ağırlıklandırma yöntemidir. Yöntemin işleyişi aşağıda denklemler eşliğinde açıklanmıştır (Bircan ve Sel, 2020: 174).

$$
\begin{aligned}
& j: \text { kriter } ;=1,2,3, \ldots, n \\
& d: \text { karar verici } ; d=1,2,3, \ldots, D
\end{aligned}
$$

İlk aşamada karar verici problemde yer alan kriterleri en önemliden en önemsize siralar.

$k$ : önemliden önemsize kriter; $k=1,2,3, \ldots, n$

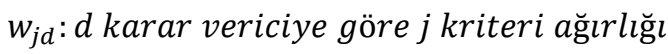

Ardından Eşitlik 1 kullanılarak her bir karar vericinin sıralamasına göre kriter ağırlıkları bulunur.

$w_{j d}=\frac{1}{n} \sum_{j=k}^{n} \frac{1}{k}$ birleştirilir.

Son olarak karar vericilerin görüşlerine dayalı olarak elde edilen ağırıklar Eşitlik 2 yardımıyla

$$
\begin{aligned}
& w_{j}: j \text { kriteri } a \breve{g} \iota r l ı \breve{g} \iota \\
& w_{j}=\sqrt[D]{\left(w_{j 1}\right)\left(w_{j 2}\right)\left(w_{j 3}\right) \ldots\left(w_{j D}\right)}
\end{aligned}
$$

\section{SMART (SIMPLE MULTI-ATTRIBUTE RATING TEChNIQUE) YÖNTEMI}

Çok Kriterli Karar Verme (ÇKKV) yöntemlerinden biri olan SMART yönteminin hesaplama süreci aşağıda verilmiştir (Lavik, 2020, 4; Patel, 2017: 3):

Eşitlik 3 karar verme problemi için başlangıç karar matrisini ifade eder.

$$
\begin{gathered}
\text { i:alternatif } ; i=1,2,3, \ldots, m \\
{\left[\begin{array}{cccc}
x_{11} & x_{12} & \cdots & x_{1 n} \\
x_{21} & x_{22} & \cdots & x_{2 n} \\
\vdots & \vdots & \ddots & \vdots \\
x_{m 1} & x_{m 2} & \cdots & x_{m n}
\end{array}\right]}
\end{gathered}
$$

Eşitlik 4 fayda yönlü kriterler için normalizasyon işlemlerinde kullanılır.

$u_{i j}: i$ alternatifinin $j$ kriteri açısından normalize fayda de $\breve{g} e r i$

$u_{i j}=\frac{x_{i j}-\min _{j} x_{i j}}{\max _{j} x_{i j}-\min _{j} x_{i j}}$ 
Eşitlik 5 maliyet yönlü kriterler için normalizasyon işlemlerinde kullanılır.

$u_{i j}=\frac{\max _{j} x_{i j}-x_{i j}}{\max _{j} x_{i j}-\min _{j} x_{i j}}$

Eşitlik 6 genel fayda değerlerinin elde edilmesi için kullanılır.

$$
\begin{gathered}
u_{i}: i \text { alternatifinin genel fayda değeri } \\
w_{j}: j \text { kriterinin ağırlı } \breve{g} \iota
\end{gathered}
$$$$
u_{i}=\sum_{j=1}^{n} w_{j} u_{i j}
$$

\section{UYGULAMA}

Bu çalışma için, Isparta Uygulamalı Bilimler Üniversitesi Bilimsel Araştırma ve Yayın Etiği Kurulu’ndan 24.09.2021 tarihli (Toplantı Sayısı: 65, Karar No:07) “Etik Kurul Onayı" alınmıştır.

Çalışmanın amacı, Borsa İstanbul Elektrik Endeksinde (XELKT) işlem gören elektrik üretimi yapan halka açık şirketlerin Covid-19 pandemi ortamındaki finansal performansını değerlendirmektir. Bu amaca yönelik olarak Borsa İstanbul bünyesindeki XELKT endeksinde işlem gören yedi adet elektrik üreten enerji şirketine ait Kamuyu Aydınlatma Platformu (KAP)' tan alınan 2020 yılı konsolide mali tablo verileri kullanılmıştır. Çalışma kapsamında kullanılan rasyoların kodları, rasyo adları ve ideal durumları Tablo 2'de verilmiştir.

\begin{tabular}{|c|c|c|c|}
\hline Rasyo Kodu & Rasyo Adı & & İdeal Durumu \\
\hline K1 & Kaldıraç Oranı (Toplam Borç / Toplam Varlık) & & Maliyet \\
\hline $\mathrm{K} 2$ & Borçlanma Oranı (Toplam Borç / Özsermaye) & & Maliyet \\
\hline K3 & $\begin{array}{llll}\text { Cari } & \text { Oran } & \text { (Dönen } & \text { Varlıklar/Kısa } \\
\text { Borçlar) } & & & \end{array}$ & Vadeli & Fayda \\
\hline K4 & Asit Test Oranı ((Dönen Varlıklar - Stoklar) / Kısa Vadeli Borçlar) & & Fayda \\
\hline K5 & Özsermaye Kârlılığı (Net Kâr / Özsermaye) & & Fayda \\
\hline K6 & Aktif Devir Hızı (Net Satışlar/Toplam Varlık) & & Fayda \\
\hline K7 & Özsermaye Devir Hızı (Net Satışlar/ Özsermaye) & & Fayda \\
\hline
\end{tabular}

Tablo 2.Rasyo Bilgileri

İlk aşamada kriter ağırlıklarını belirlemek üzere karar vericilerden bu rasyoları finansal performans değerlendirmesi açısından en önemliden en önemsize doğru sıralamaları istenmiştir. Bu sıralamalara göre her bir karar vericiye göre kriter ağılıkları elde edilmiştir. Daha sonra Eşitlik 2 yardımıyla karar vericilerin görüşleri birleştirilmiştir. Elde edilen sonuçlar Tablo 3'de verilmiştir.

Tablo 3. Kriter Ağırlıkları

\begin{tabular}{lllll}
\hline & $\boldsymbol{w}_{\boldsymbol{j} \mathbf{1}}$ & $\boldsymbol{w}_{\boldsymbol{j} \mathbf{2}}$ & $\boldsymbol{w}_{\boldsymbol{j} \mathbf{3}}$ & $\boldsymbol{w}_{\boldsymbol{j}}$ \\
\hline $\mathrm{K} 1$ & 0,3704 & 0,2276 & 0,2276 & 0,2677 \\
$\mathrm{~K} 2$ & 0,1561 & 0,1085 & 0,1085 & 0,1225 \\
$\mathrm{~K} 3$ & 0,1085 & 0,1561 & 0,0728 & 0,1072 \\
$\mathrm{~K} 4$ & 0,0728 & 0,0728 & 0,0442 & 0,0616 \\
$\mathrm{~K} 5$ & 0,2276 & 0,3704 & 0,3704 & 0,3149 \\
$\mathrm{~K} 6$ & 0,0442 & 0,0442 & 0,1561 & 0,0673 \\
$\mathrm{~K} 7$ & 0,0204 & 0,0204 & 0,0204 & 0,0204 \\
\hline
\end{tabular}

Kriter ağırlıklarının belirlenmesinin ardından Borsa İstanbul bünyesindeki XELKT endeksinde işlem gören yedi adet elektrik üreten enerji şirketine ait rasyolar toplanmıştır. Kriter ağırlıklarının toplanması ile elde edilen sonuçlara göre, K5 ile tanımlanan özsermaye kârlılığı rasyosu ilk sırada, K7 ile tanımlanan özsermaye devir hızı rasyosu son sırada yer almaktadır. Söz konusu enerji şirketlerinin isimleri ve kodları Tablo 4'te verilmiştir. 
Tablo 4. Şirket Bilgileri

\begin{tabular}{cl}
\hline Şirket Kodu & \multicolumn{1}{c}{ Şirket Adı } \\
\hline A1 & AKENERJİ ELEKTRİK ÜRETİM A.Ş. \\
A2 & AKSA ENERJi ÜRETİM A.Ş. \\
A3 & ENERJISA ENERJİ A.Ş. \\
A4 & ODAŞ ELEKTRİK ÜRETIM SANAYİ TİCARET A.Ş. \\
A5 & ZORLU ENERJİ ELEKTRİK ÜRETIMM A.Ş. \\
A6 & AKSU ENERJI VE TİCARET A.Ş. \\
A7 & AYEN ENERJI A.Ş. \\
\hline
\end{tabular}

Şirketlerin performanslarını değerlendirmek üzere toplanan veriler Eşitlik 3'te gösterilen başlangıç karar matrisin oluşturmaktadır. Tablo 5 başlangıç karar matrisini göstermektedir.

Tablo 5. Başlangıç Karar Matrisi

\begin{tabular}{cccccccc}
\hline & $\mathrm{K} 1$ & $\mathrm{~K} 2$ & $\mathrm{~K} 3$ & $\mathrm{~K} 4$ & $\mathrm{~K} 5$ & $\mathrm{~K} 6$ & $\mathrm{~K} 7$ \\
\hline A1 & 1,0190 & 53,2016 & 0,5984 & 0,5679 & 8,4109 & 0,0294 & $-1,5364$ \\
A2 & 0,5133 & 1,0545 & 1,0503 & 1,0085 & 0,1206 & 0,1261 & 0,2590 \\
A3 & 0,7101 & 2,4496 & 0,8268 & 0,8064 & 0,1520 & 0,2285 & 0,7884 \\
A4 & 0,7683 & 3,3211 & 0,4678 & 0,2928 & $-0,3160$ & 0,0696 & 0,3008 \\
A5 & 0,8925 & 8,3065 & 0,4875 & 0,4789 & 0,0166 & 0,0701 & 0,6522 \\
A6 & 0,7970 & 3,9257 & 0,1905 & 0,1726 & $-0,5405$ & 0,1303 & 0,6419 \\
A7 & 0,7378 & 2,8172 & 0,3429 & 0,3429 & $-0,1147$ & 0,0570 & 0,2176 \\
\hline
\end{tabular}

Kaynak: https://www.kap.org.tr/tr/

BIST bünyesindeki XELKT endeksinde işlem gören yedi adet elektrik üreten enerji şirketine ait KAP`tan alınan 2020 yılı yıllık konsolide mali tablo verileri kullanılarak finansal performans rasyoları hesaplanmıştır.

Elde edilen başlangıç karar matrisine Eşitlik 4 ve 5'te gösterilen işlemlerin uygulanması sonucu elde edilen değerler Tablo 6'da verilmiştir.

Tablo 6. Normalize Karar Matrisi

\begin{tabular}{cccccccc}
\hline & $\mathrm{K} 1$ & $\mathrm{~K} 2$ & $\mathrm{~K} 3$ & $\mathrm{~K} 4$ & $\mathrm{~K} 5$ & $\mathrm{~K} 6$ & $\mathrm{~K} 7$ \\
\hline A1 & 0,0000 & 0,0000 & 0,4744 & 0,4729 & 1,0000 & 0,0000 & 0,0000 \\
A2 & 1,0000 & 1,0000 & 1,0000 & 1,0000 & 0,0739 & 0,4854 & 0,7723 \\
A3 & 0,6108 & 0,9732 & 0,7401 & 0,7583 & 0,0774 & 1,0000 & 1,0000 \\
A4 & 0,4956 & 0,9565 & 0,3225 & 0,1438 & 0,0251 & 0,2017 & 0,7903 \\
A5 & 0,2501 & 0,8609 & 0,3454 & 0,3664 & 0,0622 & 0,2042 & 0,9414 \\
A6 & 0,4390 & 0,9449 & 0,0000 & 0,0000 & 0,0000 & 0,5067 & 0,9370 \\
A7 & 0,5560 & 0,9662 & 0,1773 & 0,2037 & 0,0476 & 0,1384 & 0,7545 \\
\hline
\end{tabular}

Son aşamada SMART yöntemine göre her bir şirketin genel fayda değeri Eşitlik 6 kullanılarak hesaplanır. Bu aşamada ROC yönteminden elde edilmiş olan kriter ağırlıkları devreye girmekte ve böylece ROC ile SMART yöntemleri bütünleştirilmektedir. Genel fayda değerleri ile elde edilen sıralama sonuçları Tablo 7'de gösterilmiştir.

Tablo 7.Genel Fayda Değerleri ve Sıralama

\begin{tabular}{ccc}
\hline & $\boldsymbol{u}_{\boldsymbol{i}}$ & Sira \\
\hline A1 & 0,3949 & 3 \\
A2 & 0,6308 & 1 \\
A3 & 0,5209 & 2 \\
A4 & 0,3309 & 5 \\
A5 & 0,2846 & 7 \\
A6 & 0,2865 & 6 \\
A7 & 0,3384 & 4 \\
\hline
\end{tabular}

Her bir karar vericiye göre kriter ağırlıkları elde edilip, karar vericilerin görüşleri birleştirildikten sonra normalize edilerek oluşturulan karar matrisinden genel fayda değerlerine göre AKSA Enerji Üretim A.Ş. ilk sırada, ZORLU Enerji Elektrik Üretim A.Ş. ise son sırada yer almaktadır. 


\section{SONUÇLAR}

Enerji, bir ülke ekonomisi için en önemli kaynaklardandır. Enerji kaynaklarının başında da elektrik enerjisi gelmektedir. Dünyada sanayileşmenin başlaması ile elektrik enerjisi üretiminin önemi daha da artmıştır. Elektrik enerjisi üretim potansiyeli ülke ekonomilerinin büyümesi açısından da gereklidir. Çünkü elektrik üretimi tüm sektörleri etkilemekte, özellikle de sanayi sektörünü geliştirmekte, bu gelişme de ekonomik büyümeye yansımaktadır. Ekonomik büyüme de yeni yatırımları artırmakta, bu yeni yatırımlar da daha fazla elektrik enerjisi ihtiyacı ile elektrik üretimine olan talebi artırarak, yeni elektrik üretim yatırımlarını ya da mevcut şirketlerin kapasite artırımını tetiklemektedir. Dolayısıyla elektrik üretim kapasitesi ile ekonomik büyüme arasında çift yönlü bir ilişsi bulunmaktadır. $\mathrm{Bu}$ nedenle de elektrik enerjisi üretiminin incelenmesi mevcut durumun tespiti ve uygulanacak politikalar için önem kazanmaktadır.

Ülkemizde elektrik üretim yapan pek çok şirket bulunmakta, bunlardan bir kısmı da Borsa İstanbul Elektrik Endeksinde (XELKT) işlem görmektedir. Elektrik enerjisinin son derece önemli olduğu ve özellikle de olumsuz etkileri olan Covid-19 pandemi sürecininin yaşandığ günümüzde, Borsa İstanbul Elektrik Endeksinde işlem gören elektrik üretimi yapan halka açık şirketlerin finansal performanslarının tespiti daha da önem kazanmaktadır.

Çalışmada, araştırma kapsamına alınan halka açık şirketlerin Covid-19 pandemi sürecindeki 2020 yılı yıllık konsolide mali tablo verileri kullanılarak hesaplanan finansal performans rasyoları ROC ile SMART yöntemleriyle bütünleşik olarak değerlendirilmiştir. Analiz sonuçlarına göre, AKSA Enerji Üretim A.Ş. incelenen diğer şirketlerle karşılaştırıldığında düşük borçlanma oranı ve yüksek likidite oranı ile ilk sırada yer almaktadır. Ayrıca olumlu finansal performans rasyolarında şirketin yurtdışı yatırımlarından elde ettiği, kârlılığına yansıyan döviz bazlı gelirleri de etkilidir. ZORLU Enerji Elektrik Üretim A.Ş.'nin ise 2020 yllında elektrik üretiminin düşmesi ile satışlarının azalması ve riskini yükselten artan toplam borcu finansal performans rasyolarını olumsuz yönde etkilemiş ve yapılan sıralamada son sırada yer almıştır.

Çalışma kapsamında incelenen şirketlerin kullanılan yöntemle sıralanması, şirketlerin mevcut ya da potansiyel yatırımcıları, sektör yetkilileri, politika yapıcılar ve daha pek çok paydaşa bilgi niteliği taşımaktadır. Böylece ülke ekonomileri için enerji üretiminin iyileştirilmesi ve artırılması için uygulanacak stratejiler ve politikalar açısından bir yol gösterici olması beklenmektedir.

Gelecekte yapılacak çalışmalarda BIST’te faaliyet gösteren farklı sektörlere ait şirketlerin performansları ÇKKV yöntemleri ile değerlendirilebilir. Ayrıca bu çalışmada kullanılan ROC ve SMART yöntemleri farklı konular için gerekli olan performans değerlendirmelerinde kullanılabilir. 


\section{KAYNAKLAR}

Aksaraylı, M., \& Pala, O. (2019). Uzaktan Eğitimde Kalite İyileştirme Boyutlarının Değerlendirilmesi: SMART-AHP Tabanlı SERVQUAL Yaklaşımı. Ege Academic Review, 19(2), 173-187

Ansaria, Z., Hejazib, R., Zeraatkishc, Y., \& Abadid, Z. K. M. (2021). Financial Performance Evaluation of Companies Using Decision Trees Algorithm and Multi-Criteria Decision-Making Techniques with an Emphasis on Investor's Risk-Taking Behavior. Advances in Mathematical Finance and Applications, 6(3), 112. DOI: $10.22034 / A M F A .2020 .1897171 .1405$

Arslan, H. M. (2019). SMART-TOPSIS Hibrit Yöntemi ile Personel Seçimi: Demir-Çelik İşletmelerinde Bir Uygulama. 4. InTraders Uluslararası Ticaret Kongresi Kongre Kitabı, Birinci Baskı 26 Aralık 2019 Sakarya, Türkiye, 115-126

Bae, K., Gupta, A., \& Mau, R. (2021). Comparative analysis of airline financial and operational performances: A fuzzy AHP and TOPSIS integrated approach. Decision Science Letters, 10(3), 361-374. DOI: $10.5267 / \mathrm{j} . \mathrm{ds} 1.2021 .2 .002$

Bağcı, H., \& Yiğiter, Ş. Y. (2019). BİST’te Yer Alan Enerji Şirketlerinin Finansal Performansının SD VE WASPAS Yöntemleriyle Ölçülmesi. Bingöl Üniversitesi Sosyal Bilimler Enstitüsü Dergisi, 9(18), 877-898

Barron, F.H., \& Barret, B.E. (1996). Decision Quality Using Rank Attribute Weights. Management Science, 42, 1515-1523

Beller Dikmen, B. (2021). Elektrik Enerjisi Sektörünün Finansal Performanslarının Oran Analizi Yöntemi ile İncelenmesi, İşletme Araştırmalart Dergisi, $13 \quad$ (1), 912-926. https://doi.org/10.20491/isarder.2021.1174

Darmowiyono, M., Yuliyanto, W., Purnomo, K. I., Marlini, W., Pratiwi, H., Windarto, A. P., \& Wijaya, H. O. L. (2021, February). Application of the Simple Multi Attribute Rating Technique (SMART) Method in the selection of thrush medicine products based on consumers. In Journal of Physics: Conference Series (Vol. 1783, No. 1, p. 012015). IOP Publishing. doi:10.1088/1742-6596/1783/1/012015

EMBER (2021). Data Explorer.Global Electricity Review[Erişim: 24.09.2021, https://emberclimate.org/global-electricity-review-2021/data-explorer/]

EPDK (2020).2020 Yllı Elektrik Piyasası Gelişim Raporu. [Erişim: 24.09.2021, https://www.epdk.gov.tr/Detay/Icerik/3-0-24/elektrikyillik-sektor-raporu]

Erkan, T. E., \& Elsharida, W. M. (2020). Combining AHP and ROC with GIS for Airport Site Selection: A Case Study in Libya. ISPRS International Journal of Geo-Information, 9(5), 312. DOI: 10.3390/ijgi9050312

Günen, M. A. (2021). Determination of the suitable sites for constructing solar photovoltaic (PV) power plants in Kayseri, Turkey using GIS-based ranking and AHP methods. Environmental Science and Pollution Research, 1-16. DOI: 10.1007/s11356-021-14622-x

Herişçakar, E. (1999). Gemi ana makine seçiminde çok kriterli karar verme yöntemleri ahp ve smart uygulaması. Gemi İş̧aatı ve Deniz Teknolojisi Teknik Kongresi, 99, 240-256

KAP (2021). Finansal Tablolar. [Erişim: 24.09.2021, https://www.kap.org.tr/tr/]

Konidari, P., \& Mavrakis, D. (2007). A multi-criteria evaluation method for climate change mitigation policy instruments. Energy Policy, 35(12), 6235-6257. https://doi.org/10.1016/j.enpol.2007.07.007

Lavik, M. S., Hardaker, J. B., Lien, G.,\&Berge, T. W. (2020). A multi-attribute decision analysis of pest management strategies for Norwegian crop farmers, Agricultural Systems, 178, doi: 10.1016/j.agsy.2019.102741. 1-11

Lubis, A. I., Sihombing, P., \& Nababan, E. B. (2020, June). Comparison SAW and MOORA Methods with Attribute Weighting Using Rank Order Centroid in Decision Making. In 2020 3rd International Conference on Mechanical, Electronics, Computer, and Industrial Technology (MECnIT) (pp. 127-131). IEEE 


\section{BŞEÜ Sosyal Bilimler Dergisi \\ 6 (2), 227-235, 2021}

BSEU Journal of Social Sciences

https://doi.org/10.33905/bseusbed.1005798

Mahdiana, D., \& Kusumawardhany, N. (2020, February). The Combination of Analytical Hierarchy Process and Simple Multi-Attribute Rating Technique for The Selection of The Best Lecturer. In 2020 International Conference on Smart Technology and Applications (ICoSTA) (pp. 1-5). IEEE. DOI: 10.1109/ICoSTA48221.2020.1570615695

Mercan, Y., \&Çetin, O. (2019). COPRAS ve VIKOR Yöntemleri ile BIST Elektrik Endeksindeki Firmalarının Finansal Performans Analizi. Uluslararası Afro-Avrasya Araştırmaları Dergisi, 5 (9), 123-139

Mohammed, H. J., Kasim, M. M., \& Shaharanee, I. N. M. (2017, November). Selection of suitable elearning approach using TOPSIS technique with best ranked criteria weights. In AIP Conference Proceedings (Vol. 1905, No. 1, p. 040019). AIP Publishing LLC. DOI: 10.1063/1.5012207

Moon, H., \& Min, D. (2020). A DEA approach for evaluating the relationship between energy efficiency and financial performance for energy-intensive firms in Korea. Journal of Cleaner Production, 255, 120283. https://doi.org/10.1016/j.jclepro.2020.120283

Ndruru, R. K. (2020, February). Penerapan Metode Additive Ratio Assessment (ARAS) dan Rank Order Centroid (ROC) Dalam Pemilihan Jaksa Terbaik Pada Kejaksaan Negeri Medan. In Seminar Nasional Teknologi Komputer \& Sains (SAINTEKS) (Vol. 1, No. 1, pp. 367-372)

Patel, M. R., Vashi, M. P., \& Bhatt, B. V. (2017). SMART-Multi-criteria decision-making technique for use in planning activities. Proceedings of New Horizons in Civil Engineering (NHCE-2017), Surat India.

Ribeiro, A. M. N. C., Sadok, D. F. H., da Cruz Brito, M. E., de Araújo Cavalcanti, Á., Endo, P. T., \& Kelner, J. (2020). Comparative Analysis of Current Transducers for Development of Smart Plug Through Rank Order Centroid Method. IEEE Latin America Transactions, 18(01), 147-155. DOI: 10.1109/TLA.2020.9049472

Roszkowska, W. (2013). Rank Ordering Criteria Weighting Methods-A Comparative Overview. Optimum Studia Ekonomiczne NR, 5(65). DOI: 10.15290/ose.2013.05.65.02

Sel, Ahmet (Bölüm Yazarı)., (2020), Çok Kriterli Karar Verme Problemlerinde Kriter Ă̆ırlıklandırma Yöntemleri, Bölüm 10. ROC Yöntemi, Bircan, Hüdaverdi (Editör)., Nobel Yayıncılık, Ankara

Siregar, D., Arisandi, D., Usman, A., Irwan, D., \& Rahim, R. (2017, December). Research of simple multi-attribute rating technique for decision support. International Conference on Information and Communication Technology (IconICT), IOP Conf. Series: Journal of Physics: Conf. Series 930, 012015. doi :10.1088/1742-6596/930/1/012015

Topal, A. (2021). Çok kriterli karar verme analizi ile elektrik üretim şirketlerinin finansal performans analizi: Entropi tabanlı Cocoso yöntemi. Business \& Management Studies: An International Journal, 9(2), 532546. doi: https://doi.org/10.15295/bmij.v9i2.1794 